\title{
Feasibility of Knots to Reduce the Maximum Dynamic Arresting Load in Rope Systems
}

\author{
Daniel A. Martin ${ }^{1} \cdot$ Kevin Boron ${ }^{2} \cdot$ Mark Obstalecki $^{3} \cdot$ Peter Kurath $^{2}$. \\ Gavin P. Horn ${ }^{1,2}$
}

Received: 11 February 2015/ Accepted: 27 March 2015/Published online: 7 April 2015

(C) Society for Experimental Mechanics, Inc 2015

\begin{abstract}
Impact loads to the human body due to falls from height can be mitigated by well-designed and characterized fall protection systems. While energy absorption methods using rope deformation and/or accessory components have previously been evaluated, the ability for simple knots tied in the system to alter impact loads has not been studied in detail. We quantify the effectiveness of various common knots to reduce dynamic loads in typical fall scenarios for which the systems are designed, and interpret this change in the context of rope strength reduction due to the knot. Knots are shown to significantly (45-60\%) reduce the quasistatic strength of rope when compared to a manufactured sewn-eye (40\%). A single exception to this outcome is with the quadruple overhand on a bite (30-35\%). Knots significantly reduce the maximum arresting load due to a dynamic impact event when compared to ropes without knots, providing significantly more energy absorption than the sewn-eye alone. In nearly all rope/knot combinations, the ratio of maximum arrest load (MAL) to breaking strength was lower with the knotted ropes when compared to the sewn-eye terminations. In particular, the quadruple overhand on a bite tied in the Technora-Technora rope resulted in MALs that were only $33 \%$ of the
\end{abstract}

Gavin P. Horn

ghorn@illinois.edu

1 Illinois Fire Service Institute, University of Illinois at Urbana-Champaign, 11 Gerty Drive, Champaign, IL 61820, USA

2 Department of Mechanical Science \& Engineering, University of Illinois at Urbana-Champaign, 1206 W. Green St., Urbana, IL 61801, USA

3 Sibley School of Mechanical and Aerospace Engineering, Cornel University, 105 Upson Hall, Ithaca, NY 14853, USA minimum breaking strength (MBS). Ropes with sewn-eye terminations resulted in MALs that were $80 \%$ of the MBS. From the scenarios investigated, the quadruple overhand on a bite provides a favorable reduction in arrest loads with the smallest associated loss of strength.

Keywords Dynamic arresting load · Life-safety rope · Knots $\cdot$ Strength reduction $\cdot$ Energy absorption $\cdot$ Fire Service

\section{Introduction}

Falls from heights may result in immense impact forces for unprotected personnel spurring the development of fall protection technologies, many of which are rope based. In order for these systems to operate safely, dynamic strength and energy absorption capabilities of these systems must be characterized. Biomechanically dangerous dynamic loading can still occur with these rope systems if they are not properly designed. Life safety rope applications require a tradeoff between system elongation that absorbs the energy of a fall with extended fall distances that may allow an impact before the rope arrests the fall. OSHA standards mandate that fall protection and rope systems must limit the fall arresting load conveyed to any individual wearing a body harness to below $8 \mathrm{kN}$ [1]. It has been suggested that the maximum fall arresting limit should be reduced to $2.75 \mathrm{kN}$ when wearing a "seat harness" [2] based on a study by Magdefrau. He showed that dynamic forces as low as $4 \mathrm{kN}$ may be large enough to cause spinal fractures for falls arrested while wearing these harnesses [3]. In many applications, elastic deformation of dynamic ropes and/or secondary energy absorbers are employed to reduce the arresting load transferred to the user to reduce the risk 
of injury from dynamic loading. A great deal of research has been conducted to characterize the quasistatic and dynamic strength and energy absorption characteristics of ropes used in the maritime industry [4-8], industrial fall protection $[9,10]$, recreational sport climbing [11-14] and even in single polymer strands $[15,16]$. Secondary components (that remove energy from the system through controlled failure, friction, or deformation as they are loaded) have been shown to reduce the impact load on the individual to a safer range [17-20].

Personal escape rope systems are increasingly utilized in firefighter personal protective equipment (PPE) due to firefighter line of duty deaths and injuries that resulted from firefighters being forced to jump from elevated levels of a structure without fall protection equipment (e.g. [21]). Much like traditional fall protection, escape rope systems need to be light weight, compact, and wear resistant. In addition, they must withstand extreme thermal environments [22] and be worn on the body for long periods of time prior to being easily and rapidly deployable in an emergency situation. To meet these requirements most escape ropes are constructed from para-aramid fibers such as Technora or Kevlar. Due to their high stiffness, the maximum dynamic arresting load is much higher than those generated using more compliant traditional polymer ropes for the same fall distance [23].

Techniques for decreasing impact forces in rope systems are varied, but typically rely on controlled deformation, failure of structural elements, or frictional dissipation through slippage between components. A firefighter must carry the system during daily operations; so commercially available energy absorption systems that are relatively heavy and bulky have seen limited adoption. Descent control devices that allow rope slippage and are incorporated into some escape systems, are required to limit the maximum impact force to less than $8 \mathrm{kN}$ by NFPA 1983 standards [24]. However, these devices are not universally used and may be compromised in hasty escape scenarios where ropes may be tangled. With the thermal range of performance and ease of deployment restrictions expected for Fire Service escape rope systems, adding secondary energy absorbers like those used in industrial fall protection are not operationally viable alternatives. Therefore, the need to incorporate compact energy absorption mechanisms into escape systems presents a complex challenge.

Utilizing knots within a rope may allow rope to slip past itself under load and create a self-imposed frictional dissipation of energy. In the lay literature, the incorporation of a knot(s) into rope systems has been discussed in anecdotal terms without experimental justification [25, 26]. A review of the academic literature has found no information on the incorporation of knots as energy absorbers in rope systems. However, it has been well established that knots result in an overall loss in quasistatic strength for rope systems used in the maritime industry [27], single polymer strands or sutures [28, 29], and recreational sport climbing ropes [11, $25,30]$.

Marbach and Tourte [25] suggest that quasistatic strength of climbing rope for cave exploration can decrease by $35-50 \%$ depending on the size of rope and type of knot. Milne [27] measured a $24 \%$ reduction in strength when a figure-8 loop is utilized as a termination knot in $8 \mathrm{~mm}$ polyester ropes used for sailing rigging. Using the same figure-8 loop termination knot tied with a $10 \mathrm{~mm}$ Beal Tiger polyamide climbing rope, Brown [30] found a $16 \%$ decrease in overall strength. Ultimate knot failure is typically located at the entrance of the knot where the most rope overlapping exists [25, 29]. Marturello [29] also suggests that performance of a suture increases as the knot gets larger (more wraps). Based on the results from a pilot study [31], incorporating a single in-line figure-8 knot dropped the minimum breaking strength (MBS) of the stiffest Fire Service escape rope by $60 \%$ while the strength of the more compliant rope only dropped $36 \%$. Utilizing the same knot with the stiffest rope, the overall arresting load was reduced by $27 \%$ [31].

This study will characterize the impact of several common knots on rope strength and their ability to reduce maximum arrest load (MAL) compared to ropes that utilize commercial sewn-eye terminations. With these high performance ropes, which cannot absorb sufficient energy by deformation alone, incorporating a knot may provide an operationally viable solution to reducing impact loads to safe levels. This data provides the first publication of the combined effects of knots on strength and energy absorption and can be replicated in other rope systems of occupational or recreational interest.

\section{Experiment}

\section{Specimen}

Two commercially available $7.5 \mathrm{~mm}$ ropes of kernmantle construction, certified as escape rope via NFPA 1983 [24], are utilized in this study: one constructed from a Technora sheath and Technora core (Technora-Technora) and another built from a Technora sheath and nylon core (Technora-Nylon). The Technora-Technora rope has very high strength and heat resistance [22], but also high stiffness resulting in large dynamic loading from an impact event [23]. Technora-Nylon provides a unique combination of relatively high heat resistance, abrasion resistance and strength, and improved energy absorption capabilities due to its approximately $4 \times$ lower stiffness [23]. Every specimen used in this study is made from virgin rope, stored in the laboratory, and tested at room temperature. Both ropes are tested with a variety of termination configurations: (1) 
virgin rope with clamped ends (baseline condition for these tests), (2) manufacturer provided sewn-eye, (3) figure- 8 on a bite, and (4) quadruple overhand on a bite, and several knots incorporated in-line (with clamped end terminations), including: (5) figure-8, (6) two figure-8s in line (equally spaced between ends), (7) double overhand, and (8) quadruple overhand. Figure 1 shows example test samples prior to final dressing in order to better visualize the knot geometry. The latter 4 knots allow assessment of the effect of different configurations of the same knots in scenarios that can be used when sewn-eye terminations must be included to securely fasten the rope to the anchor in manufactured systems. As can be seen in Fig. 1, compared to the overhand knots, the figure- 8 knot will result in a tighter bend where the rope enters the knot body, resulting in a smaller minimum radius and larger load concentrations. Furthermore, comparing configurations 5 and 6 provides the ability to estimate the effect of two identical
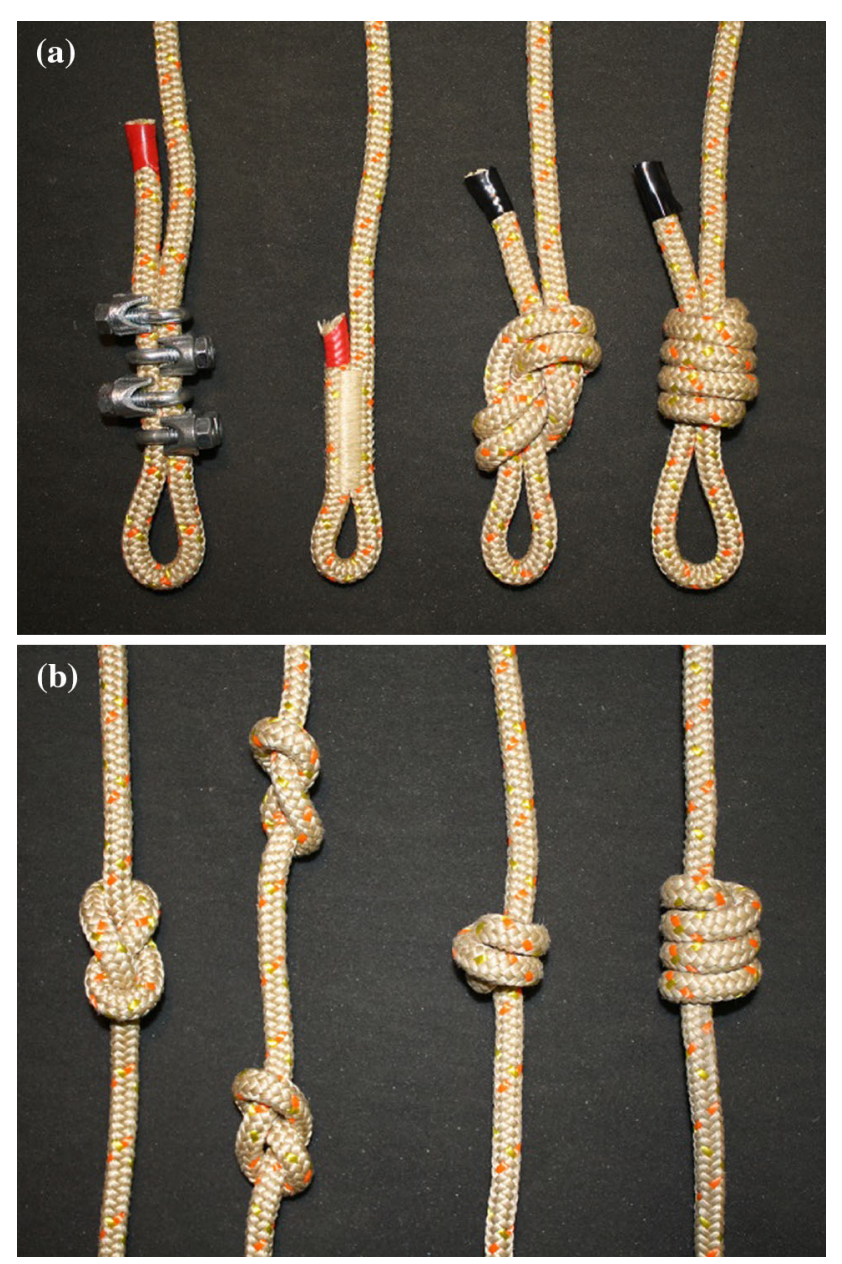

Fig. 1 Knots tested during this study: a termination configurations (L-R) virgin rope with clamped ends; manufacturer provided sewneye; figure- 8 on a bite; quadruple overhand on a bite, and $\mathbf{b}$ in-line knots (L-R) figure-8; two figure-8s in line; double overhand; quadruple overhand knots that do not interact with each other. As such, these knots incorporate twice as much rope into the knot structure, but the load transfer within the individual knots is not affected. Configurations 7 and 8 can be compared to understand the effect of doubling the amount of rope involved in the knot body, but in a way that significantly spreads the load over more rope in the body. All knots are tied by the same researcher to ensure uniform dressing prior to testing.

Both quasistatic and dynamic tests were conducted on each rope/knot combination, requiring different means of attachment to the test apparatus. During the quasistatic tests the ropes are wrapped around drum style grips [24] which are secured to each crosshead of the load frame in order to reduce the propensity for the rope to fail at the load frame attachment point. When testing in-line knots, the knots are tied in the middle of the gage length between each drum grip. Tests of termination knots were conducted with the knot tied on a bite with a steel thimble in the loop, which successfully eliminated failures at the bite. The knot is secured to the top (stationary) crosshead with a pin connection while the free end is wrapped around a drum grip.

The dynamic test samples are prepared in a nearly identical manner with the exception that they are secured to the drop test apparatus and drop weight utilizing a pin connection through a steel thimble in the bite as opposed to drum style grips. The standard drum style grips are not feasible for this application due to their weight and slip inherent in these fixtures.

\section{Testing Apparatus}

Quasistatic tests are conducted using a $44.5 \mathrm{kN}$ screw-driven load frame operated at a constant crosshead speed of $5.4 \mathrm{~mm} / \mathrm{s}$. Data is sampled at $10 \mathrm{~Hz}$ using a NI-USB-6251 data acquisition system with LabVIEW data acquisition software (National Instruments, Austin, TX, USA). Test scenarios are typically repeated three times, though in some cases additional tests are conducted if inconsistent performance is detected. The minimum breaking strength (MBS) of each rope is calculated as defined by NFPA 1983 [24]:

$\mathrm{MBS}=\mu-3 * \mathrm{SD}$

where $\mu=$ mean failure load (calculated as the arithmetic average) and $\mathrm{SD}=$ standard deviation (square root of the sample variability). While NFPA 1983 [24] and other certification of life safety systems requires five replicates, three repeats were conducted here due to the large number of samples analyzed. For the purposes of this research, the three samples were deemed to provide sufficient information to draw general conclusions and encourage more focused investigation.

For the dynamic tests, a multifunctional dynamic drop apparatus is employed [23]. During these tests an unguided 
free vertical drop configuration is utilized. A 0.25 fall factor (FF, the distance travelled by a falling mass divided by the overall rope gage length [32]) is utilized. The rope gage length is $60 \mathrm{~cm}$ (after knots have been incorporated) with a $15 \mathrm{~cm}$ drop, simulating a typical payout scenario that may be encountered in the Fire Service [24]. A quick release clamp (Sea Catch TR3, Gig Harbor, WA) is utilized to ensure safety and repeatability of the drop. The $84 \mathrm{~kg}$ drop mass is constructed of Olympic weight plates in accordance with the UIAA Standard 101 for dynamic rope testing [33]. This load is less than the $136 \mathrm{~kg}$ employed in NFPA 1983 standards [24] to test descent control devices. The $84 \mathrm{~kg}$ mass was selected for these tests in order to minimize the likelihood of system failure due to highly localized stress in the knots. It was desired to highlight the differences in energy absorption capabilities of the various systems during these tests without introducing failure as a variable. Hypothetically, the arresting loads would scale in a roughly linear manner with larger test loads [34-37], though this is expected to be a conservative or upper bound estimate.

To measure the dynamic arresting loads generated during testing, a $45 \mathrm{kN}$ load cell (Omega, LCCD-10 K, Stamford, CT) is employed as the attachment point for the specimen fixed to the structure simulating an anchor (Fig. 2). Data is sampled at $1 \mathrm{kHz}$ using the National Instrument and LabVIEW data acquisition system utilized for the quasistatic test apparatus. The MAL is identified from each test as the peak load recorded.

\section{Results and Discussion}

\section{Quasistatic Failure Loads in Knotted Ropes}

The significant reduction in quasistatic failure loads upon introduction of manufactured sewn-eyes and various knots is apparent in Table 1 for Technora-Technora rope and Table 2 for Technora-Nylon rope. With the sewn-eye

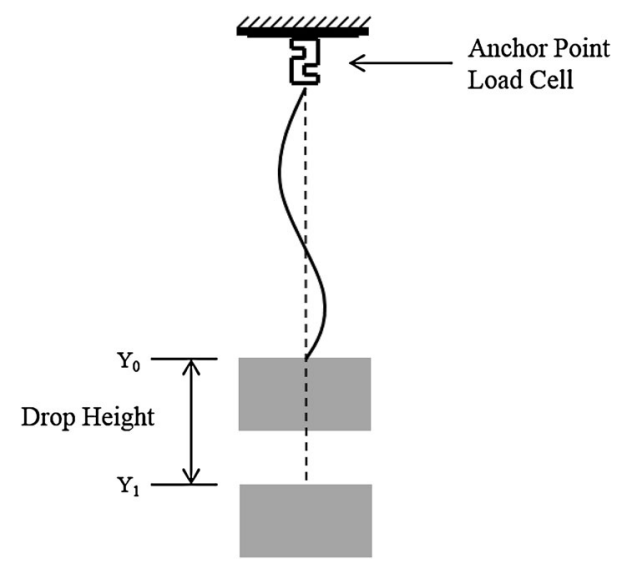

Fig. 2 Schematic of the vertical dynamic drop test termination, which is commonly incorporated in many commercial rope systems, MBS is reduced by approximately $40 \%$ in both ropes. By comparison, terminating the rope with a figure- 8 on a bite resulted in a more significant $56 \%$ reduction in strength for the TechnoraTechnora rope and slightly larger $45 \%$ reduction in Technora-Nylon. On the other hand, the quadruple overhand on a bite reduced MBS by only 30 and $34 \%$ for the same ropes, resulting in MBS values $2.8 \mathrm{kN}$ (TechnoraTechnora) and $0.8 \mathrm{kN}$ (Technora-Nylon) higher than the values obtained for manufactured sewn-eye terminations. Additionally, the more gradual rope bend and distributed pressure of the quadruple overhand results in a significantly stronger knot than the figure- 8 , with MBS increasing from 11.3 to $17.8 \mathrm{kN}$ (figure-8 vs quadruple overhand) for Technora-Technora and 9.6 to $11.4 \mathrm{kN}$ (figure-8 vs quadruple overhand) for Technora-Nylon.

The measured reduction in MBS for the figure- 8 on a bite is considerably higher than similar tests conducted in traditional polymer ropes used in sport climbing (16\%) [30] and sailing (24\%) [27], which can be attributed to differences in rope construction, material, and diameter. The above referenced ropes are constructed from a more compliant material than the Technora based rope systems studied here. We have shown that these ropes do not absorb the energy as efficiently as the more compliant traditional polymer ropes made from $100 \%$ nylon [23]. As more Technora is added to the ropes (from $100 \%$ nylon to Technora-Nylon to $100 \%$ Technora), stiffness increases [23] and the ability to tolerate the sharp bend in the figure- 8 knot is reduced. Strength reduction for a given knot is also expected to be more significant for smaller ropes [25], and the tested ropes in this study were $7.5 \mathrm{~mm}$ compared to the $10 \mathrm{~mm}$ diameter rope used in Brown's study [30].

Importantly, the standard deviation of the sewn-eye data is $2-5 \times$ higher than that measured with the knot terminations. The large variability in the sewn-eye samples can be attributed to inconsistencies in the fabrication of the end condition. Even though the sewn-eyes were constructed by the same manufacturers of their respective ropes, the placement of the stitching and transfer between the load carrying components of each leg of the rope can be significantly variable due to interactions between the threads. The sewn-eye in both cases uses stiff and relatively brittle Technora thread. The quadruple overhand on a bite is more deterministic than the manufactured sewn-eye in terms of predicting the range of potential failure.

By adding a simple figure- 8 knot, located in the center of the rope, MBS is reduced by $60 \%$ for TechnoraTechnora and $50 \%$ for Technora-Nylon. For the Technora-Technora rope, the figure- 8 knot configuration resulted in a similar reduction in MBS regardless of whether one or two knots were tied in the rope gage section. On the 
Table 1 Quasistatic failure loads and MBS for TechnoraTechnora rope

\begin{tabular}{lllll}
\hline Rope & Configuration & Mean failure \pm SD $(\mathrm{kN})$ & MBS $(\mathrm{kN})$ & \% Change in MBS \\
\hline Rope termination & Virgin rope & - & 25.6 & - \\
& Sewn-eye & $20.9 \pm 1.9$ & 15.0 & -41 \\
& Figure-8 [31] & $13.6 \pm 0.8$ & 11.3 & -56 \\
& Quadruple overhand & $18.9 \pm 0.4$ & 17.8 & -30 \\
In-line knot & & & \\
& Figure-8 & $12.6 \pm 0.8$ & 10.3 & -60 \\
& Figure-8-figure-8 & $11.7 \pm 0.3$ & 10.8 & -58 \\
& Double overhand & $12.5 \pm 0.2$ & 11.8 & -54 \\
& Quadruple overhand & $15.8 \pm 0.6$ & 13.8 & -46 \\
\hline
\end{tabular}

Table 2 Quasistatic failure loads and MBS for TechnoraNylon rope

\begin{tabular}{lllcl}
\hline Rope & Configuration & Mean failure $\pm \mathrm{SD}(\mathrm{kN})$ & MBS $(\mathrm{kN})$ & \% Change in MBS \\
\hline Rope termination & Virgin rope & \multicolumn{1}{l}{. } & 17.3 & \multicolumn{1}{l}{-} \\
& Sewn-eye & $16.2 \pm 1.9$ & 10.6 & -39 \\
& Figure-8 [31] & $11.4 \pm 0.6$ & 9.6 & -45 \\
& Quadruple overhand & $14.4 \pm 1.0$ & 11.4 & -34 \\
In-line knot & Figure-8 & $9.7 \pm 0.4$ & 8.6 & -50 \\
& Figure-8-figure-8 & $9.3 \pm 0.4$ & 8.2 & -53 \\
& Double overhand & $9.0 \pm 0.5$ & 7.4 & -57 \\
& Quadruple overhand & $10.0 \pm 0.2$ & 9.5 & -45 \\
\hline
\end{tabular}

other hand, strength was reduced by $54 \%$ for the double overhand and $46 \%$ with the quadruple overhand. For the Technora-Nylon rope, the one and two knot figure- 8 configurations again both resulted in a reduction of MBS by approximately $50 \%$, while the double overhand and quadruple overhand reduce strength by 57 and $45 \%$, respectively. For the ropes tested here, adding a second knot of identical size and bend radius that does not interact with the first (one vs two figure-8s in-line) has no effect on strength. However, when the double overhand is expanded to a quadruple overhand, which uses the same geometry, but spreads the internal tightening load over a larger area of the knot structure, MBS increases substantially. These results expand upon the findings by Marturello [29] who showed improved quasistatic strength in knotted polymer sutures as the number of throws in the knot increases. Additionally, we found that the single figure- 8 or quadruple overhand tied on a bite for the rope termination resulted in a higher strength construct than when tied in-line. The knots tied on a bite included two lengths of rope in the body, resulting in a larger minimum bend radius than the in-line knots.

Finally, according to NFPA 1983 standards, escape rope MBS at room temperature must exceed $13.3 \mathrm{kN}$. Baseline tests with bollards demonstrate that both virgin ropes tested easily exceed this value (Tables 1,2 ). However, when terminations or knots are tied in the rope, the only configurations that can maintain this level of MBS are the TechnoraTechnora ropes with the sewn-eye or quadruple overhand knots (termination or in-line). The $13.3 \mathrm{kN}$ strength requirement is intended to provide a low probability of failure given the single person load expected on the rope. The large reductions in MBS observed for end terminations alter this seemingly large factor of safety, leaving a reduced reserve load carrying capacity for dynamic loads and/or environmental effects such as sharp edges and elevated temperatures.

\section{Dynamic Testing}

The maximum loads generated during dynamic testing using a $0.25 \mathrm{FF}$ scenario can be compared to the quasistatic strength determined in the previous section under the assumption that rope strength is not rate-dependent. This assumption is expected to be valid within the range of rates tested here for the stiff, high melting point Technora based samples [23]. However, this same comparison may not be appropriate in rate dependent rope systems such as $100 \%$ nylon ropes (for example). While we seek to find rope/knot combinations that result in high MBS values, in the scenarios tested here, a lower MAL is desired for most efficient performance.

\section{Baseline Clamped Ends Versus Sewn-Eyes}

As a baseline experiment, a series of dynamic tests were conducted with samples terminated by the wire rope clamps on both ends and another series where one end was clamped and the other terminated by manufacturer supplied 
Table 3 Maximum arresting loads (mean $\pm \mathrm{SD}$ ) for Technora-Technora and Technora-Nylon with various knots

Fig. 3 Initial dynamic loadtime characteristics of various knots tied in a TechnoraTechnora rope undergoing a $0.25 \mathrm{FF}$ vertical drop

\begin{tabular}{llll}
\hline & Configuration & Technora-Technora $(\mathrm{kN})$ & Technora-Nylon $(\mathrm{kN})$ \\
\hline Rope termination & Clamped & $10.4 \pm 0.7$ & $6.7 \pm 0.1$ \\
& Sewn-eye & $12.1 \pm 0.1$ & $5.7 \pm 0.1$ \\
& Figure-8 [31] & 8.1 & 4.3 \\
& Quadruple overhand & $5.8 \pm 0.1$ & $4.0 \pm 0.3$ \\
In-line knot & Figure-8 [31] & 7.8 & 4.0 \\
& Figure-8-figure-8 & $6.4 \pm 0.4$ & $3.9 \pm 0.1$ \\
& Double overhand & $7.6 \pm 0.2$ & $4.2 \pm 0.1$ \\
& Quadruple overhand & $6.1 \pm 0.1$ & $3.9 \pm 0.1$ \\
\hline
\end{tabular}

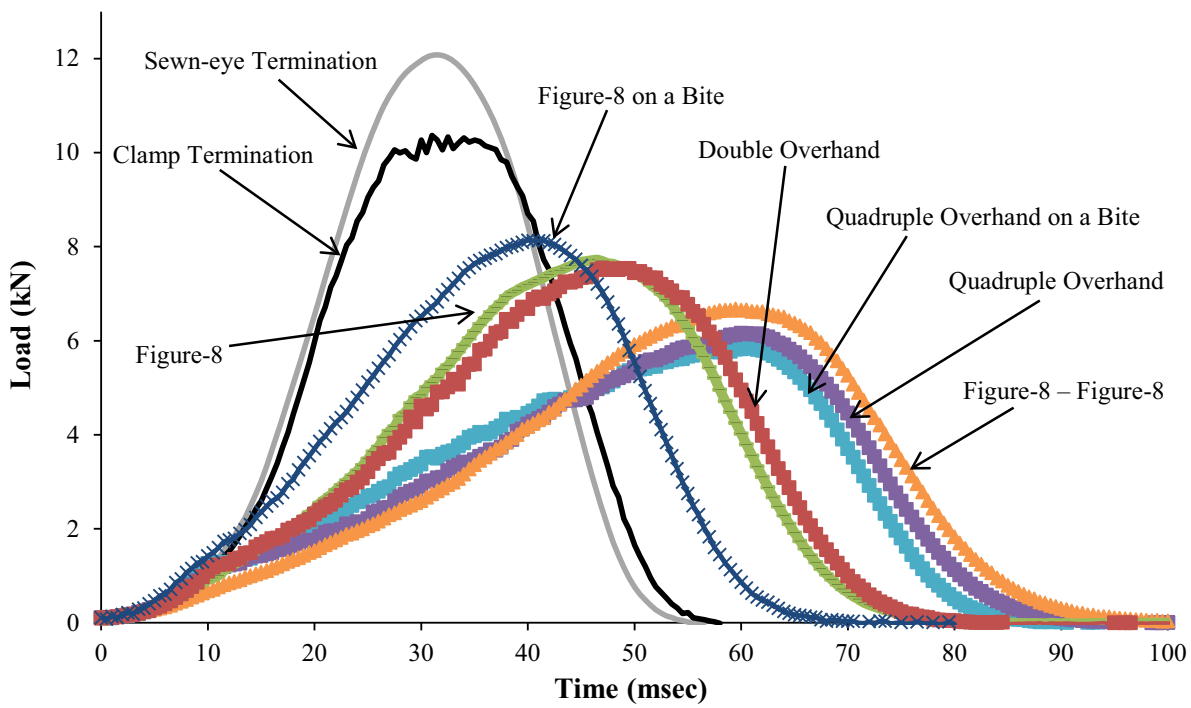

commercial sewn-eyes (Table 3). For the TechnoraTechnora samples, the dynamic load-time curves (Fig. 3) for the 'Clamp Termination' and 'Sewn-eye Termination' configurations are similar during the loading portion up to approximately $8 \mathrm{kN}$; after which the clamped configuration becomes more compliant followed by a nearly isostatic deformation at approximately $10 \mathrm{kN}$. For the TechnoraTechnora samples, the sewn-eye configuration produces a $1.7 \mathrm{kN}$ higher arresting load in the tests conducted here. This behavior is a result of the slight, but measurable slippage within the clamps $(0.3-0.6 \mathrm{~cm})$ that provided an additional means of energy absorption due to frictional dissipation compared to the sewn-eye which firmly secured the sheath and core for the loads experienced in these drop tests. The maximum achieved load and slip were consistent for all tests conducted with these clamps. As will be seen in the next section, samples tested with knots did not reach the load where slippage is expected in these clamps. Hence, even when using these clamps for ends not terminated by a knot, this behavior should not affect results from the knotted samples.

For the Technora-Nylon tests, the increased compliance of the rope system [23] resulted in longer times to maximum load and lower MAL compared to similar Technora-Technora configurations (Fig. 4). Dynamic loads measured with sewn-eye terminated ropes were approximately $1 \mathrm{kN}$ lower than those measured from tests with the clamps. Additionally, the rope system with the sewn-eye was structurally more compliant than the clamped structure. Due to the variability in manufacturer's construction of factory sewn-eyes demonstrated by the relatively high deviations in failure strength (Table 2) and the difficulty of obtaining factory sewn-eyes for our specimen configuration, clamps were selected to secure the terminal ends of the rope other than those terminated by knots. The end clamped configuration will reduce scatter and allow more insight into the effect and variability of knots considered in this study.

\section{Energy Absorption via Knots}

The MAL generated by 0.25 fall factor in samples that incorporate knots are significantly reduced compared to the baseline tests using clamped and sewn-eye terminations. For the termination knots in the Technora-Technora samples, MAL drops from $10.5 \mathrm{kN}$ with the end 
Fig. 4 Initial dynamic loadtime characteristics of various knots tied in a Technora-Nylon rope undergoing a $0.25 \mathrm{FF}$ vertical drop

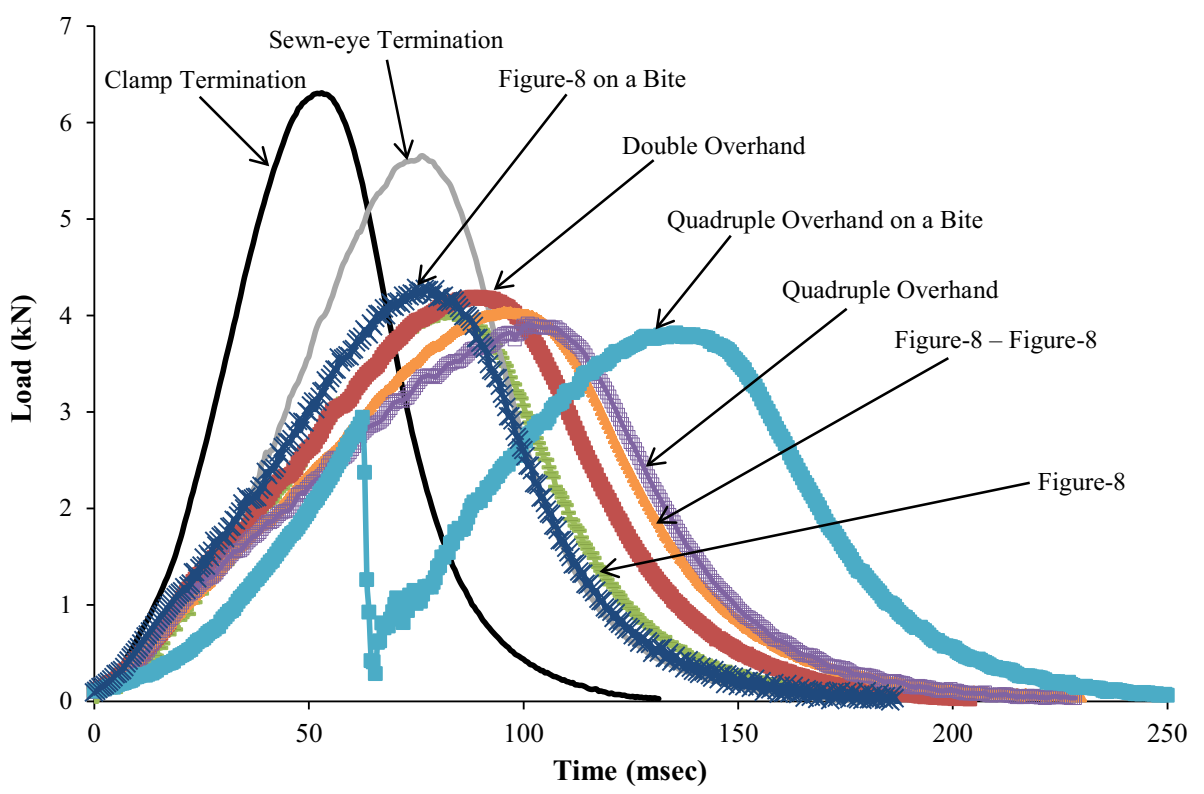

clamps (which did allow some slip) and $12.1 \mathrm{kN}$ with the sewn-eye to 8.1 and $5.8 \mathrm{kN}$ with the figure- 8 and quadruple overhand end terminations, respectively. Incorporating the same knots in the Technora-Nylon samples results in a reduction in the MAL from 6.7 and $5.7 \mathrm{kN}$ for the clamped and sewn-eye configurations to approximately $4.0 \mathrm{kN}$ for either knotted end termination. The ratio of MAL to MBS can provide a simple estimate of the percentage of rope system strength utilized during the dynamic loading scenario. In other words MAL/MBS ratio can be interpreted as an estimate of either the knot efficiency or reserve strength. Compared to the sewn-eye configuration the MAL/MBS ratio is improved (smaller) for all termination knots, most notably for the Technora-Technora samples. The standard $0.25 \mathrm{FF}$ drop with the $84 \mathrm{~kg}$ drop mass resulted in dynamic loads that were more than $80 \%$ of the static MBS with the sewn-eyes, yet were only $33 \%$ of the MBS when terminated with a quadruple overhand. Assuming that the dynamic impact load scales linearly with the drop mass [34], the NFPA 1983 standard $136 \mathrm{~kg}$ drop mass could result in an extrapolated MAL that would exceed the MBS of the sewn-eye termination ( $\sim 19.6 \mathrm{kN}$ or $\sim 130 \%$ of the sewn-eye MBS), while the quadruple overhand termination configuration would result in an extrapolated MAL $(\sim 9.4 \mathrm{kN})$ that is only $53 \%$ of the MBS of the knotted Technora-Technora rope. Weber and Hudson [35-37] have studied the question of linearity of this relationship as the load increases, particularly with the lower elongation ropes. While additional research is needed in this area, the assumption of linearity is adequate for the purpose of this investigation.
Including a knot in-line with the clamped end configuration was also shown to significantly reduce MAL compared to the baseline configurations for both ropes (Table 3; Figs. 3, 4). Adding the single figure-8 or double overhand both resulted in similar reductions in the arresting load: approximately 7.7 and $4.1 \mathrm{kN}$ for the TechnoraTechnora and Technora-Nylon samples, respectively. Increasing the amount of rope engaged in the knots with two figure- $8 \mathrm{~s}$ in-line or using a quadruple overhand further reduced the mean arrest loads to approximately 6.3 and $3.9 \mathrm{kN}$ respectively. These values are all comparable to energy absorption capabilities of the termination knots with similar length of rope engagement (i.e. figure- 8 on a bite is comparable to in-line figure- 8 and in-line double overhand while quadruple overhand on a bite is comparable to in-line double figure- 8 and in-line quadruple overhand). The sewn-eye in the Technora-Nylon ropes in tandem with these knots may provide further reduction in the dynamic loading that might be transferred to the firefighter and reduce the probability of failure in the rope.

Incorporating these knots into the most basic escape system can provide an important energy absorption mechanism when compared to the $8 \mathrm{kN}$ MAL stipulated by the NFPA standard. Drop tests conducted using TechnoraTechnora rope terminated with clamped ends or sewn-eyes resulted in impact loads well above this limit. However, a single knot-in-line or as a termination - can reduce these loads below this $8 \mathrm{kN}$ limit with the $84 \mathrm{~kg}$ drop mass. Larger knots such as the double figure- 8 or quadruple overhand further reduce MAL well below this value. In all cases, the Technora-Nylon rope tests resulted in loads below $8 \mathrm{kN}$, and the knots were successful in reducing MAL to approximately $4 \mathrm{kN}$ with the $84 \mathrm{~kg}$ drop mass 
tested. Sulowski suggests that mean arrest forces above this $4 \mathrm{kN}$ level can result in "severe injuries" when the rope is attached in the manner firefighters will be using Class 2 harness and ladder belts [2]. However, none of these rope and knot configurations reduce the loads below the most stringent $2.75 \mathrm{kN}$ recommendation [2]. All knots considered appear to provide an important option for reducing the risk for injuries to firefighters. This comparison should be interpreted with the understanding that these tests were conducted with an $84 \mathrm{~kg}$ drop mass (as opposed to the $136 \mathrm{~kg}$ mass required by the NFPA 1983) in order to study the impact of knots on energy absorption without the risk of rope failure.

The reduction in MAL with larger knots is partially attributed to the introduction of additional length of rope, which lowers the apparent stiffness of the system. The extended knot structure allows greater contact surface area for friction interactions to remove energy. There may be other, larger knots that result in even further reductions in dynamic loads, but the Fire Service is constrained by operational realities where these knots may be too bulky and difficult to deploy safely in an emergency situation.

Load-time characteristics of the impact tests in various knot and rope configurations provide insight into the energy absorption mechanisms. For the Technora-Technora rope (Fig. 3) all of the curves are nearly identical up to approximately $1.1-1.3 \mathrm{kN}$, after which the knotted samples experience a noticeable change in slope. The curves suggest that the knots have an "activation load" where the load is sufficient enough to overcome the static friction within the knot. After that point, the kinetic friction within the knot begins generating heat and reduces the load.
Unlike the baseline clamped and sewn-eye curves that are nearly symmetric about the peak load, the knotted samples are much more compliant (shallower slope) during loading than unloading due to frictional dissipation. This asymmetry is larger for the knots with more rope involvement (quadruple overhand, double figure-8) where the peak load is reduced in magnitude and shifted to longer times in the deformation process. The non-recoverable nature of frictional dissipation is a desirable feature of this approach. Energy dissipation due to recoverable system stiffness will cause bounce back as demonstrated in the extreme case of bungee jumping. However, this mechanism will only provide energy dissipation for a single fall event and will likely have to be replaced afterwards. If, for example, an escape system is used for training, the original knot should be considered to have a decreased capacity for absorbing energy.

The load-time characteristics of the Technora-Nylon ropes (Fig. 4), display different behavior than TechnoraTechnora. The baseline clamped configuration is significantly stiffer than any of the other test scenarios, most likely due to the lack of deformation in the termination. However, the sewn-eye and knot configurations (other than quadruple overhand on a bite) all have similar initial loading characteristics up to approximately $1.5 \mathrm{kN}$, where knot slippage apparently changed the compliance of these samples. The higher activation load with this rope may be attributed to its softer handling properties ('hand') that allows tighter dressing of the rope and improved compaction of the knot. The overall time to reach maximum load has increased by $\sim 2.5 \times$ compared to the identical Technora-Technora system because of the reduced
Fig. 5 Load-time curves for the Technora-Nylon samples with a quadruple overhand on a bite termination knot

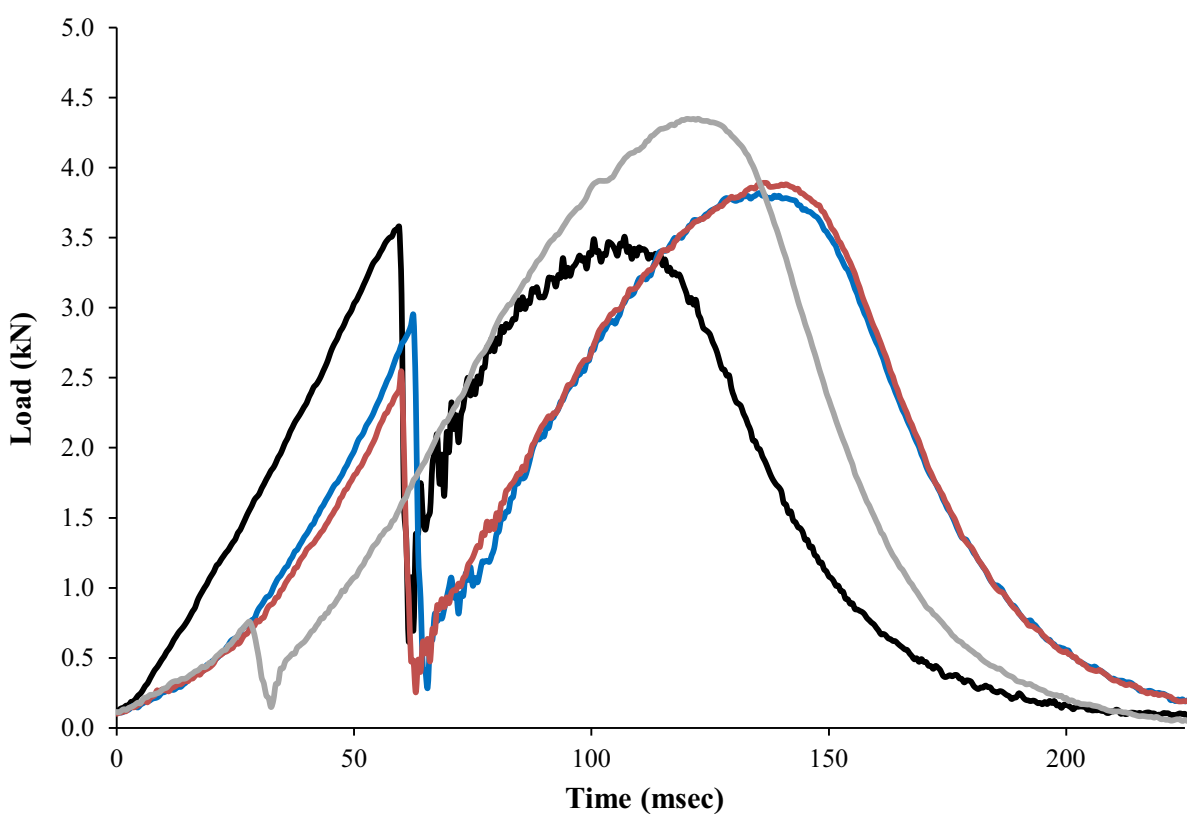


stiffness of the nylon core. Again, the asymmetry in loading and unloading behavior and a shift towards more elongation for the larger knots are noted, but the differences between the 'single' and 'double' knots are not as significant. As suggested by the similar MAL, frictional dissipation in these ropes with softer hand is more consistent; though more detailed study is required to determine the exact mechanism.

For the Technora-Nylon ropes, the quadruple overhand on a bite load-time characteristics are unique. These samples were initially more compliant that the other knotted specimens, with an increase in load at a lower rate, suggesting increased compliance early in the deformation for this rope/knot combination. At about $2.5-3.5 \mathrm{kN}$ (60 $\mathrm{ms}$ ) the load drastically decreases as the static friction within the knot is overcome. During this $3 \mathrm{~ms}$ period, the load drops to approximately $0.5 \mathrm{kN}$ before the knot again catches and the load is transmitted at a higher rate (slightly more stiff structure). The quadruple overhand slides a few millimeters to tighten around the load pin during this load drop. This "stick-slip" behavior is consistently present for all quadruple overhand on a bite specimens (Fig. 5), though some variation can be seen due to slight differences in dressing of the knot and termination loop dimensions.
Fig. 6 Representative dynamic (Dyn) and quasistatic (QS) loadtime curves for the a TechnoraTechnora and b TechnoraNylon samples with the overhand knot series (a)
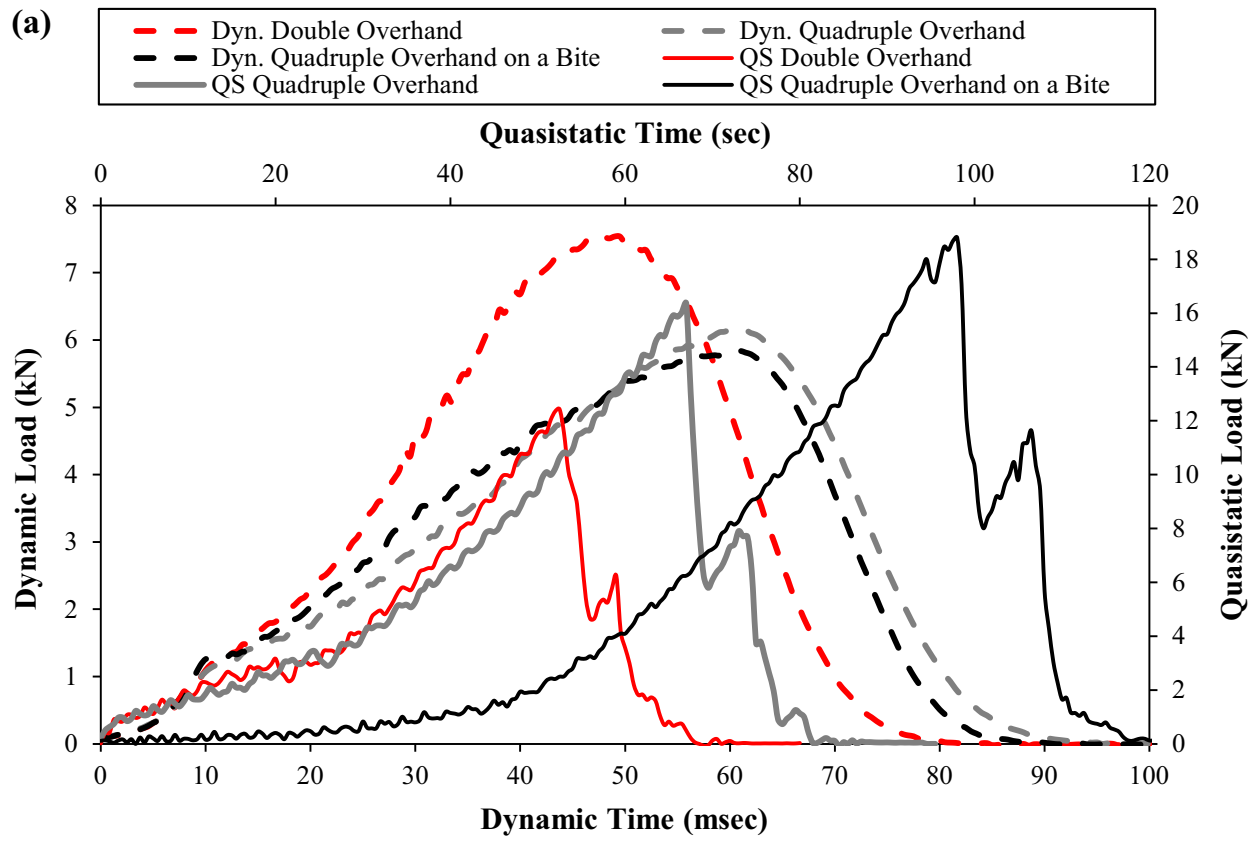

(b)

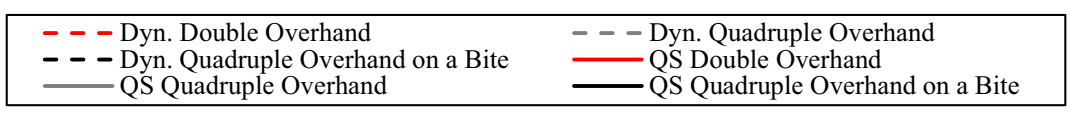

Quasistatic Time (sec)

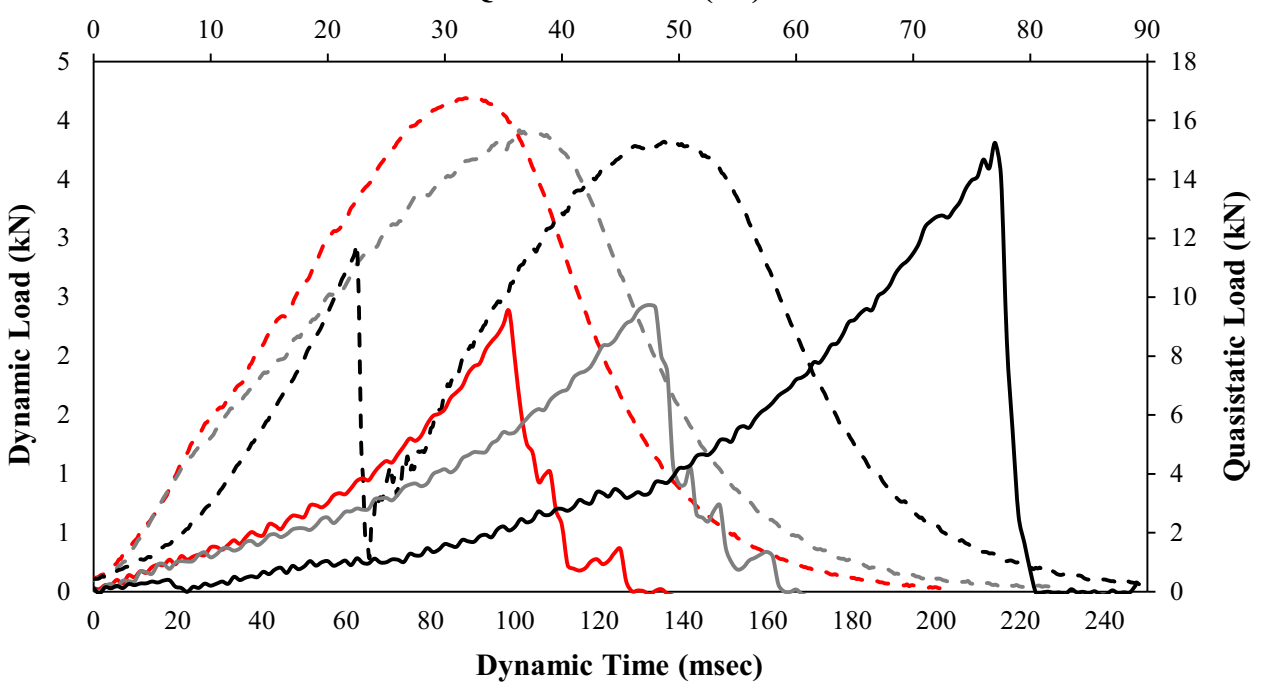


This behavior was also present in Technora-Technora rope, though not nearly as noticeable as that for the Technora-Nylon rope.

Characteristics of failure and arrest behavior of the knotted ropes undergoing quasistatic and dynamic loading have some similarities in many regards despite roughly the 3 orders of magnitude difference in loading rates. For example, Fig. 6 provides a comparison between typical results from the overhand knot series (double and quadruple overhand in-line and quadruple overhand on a bite) for both ropes tested. In each case the samples tested with the double overhand knot resulted in the maximum dynamic load being reached earlier than either quadruple overhand. Similarly, in the quasistatic test, these ropes resulted in the stiffest configuration (load increases more rapidly due to less rope incorporated in the body), with the lowest failure loads. Dynamic loads are slightly smaller in the quadruple overhand on a bite coincident with more compliant behavior in quasistatic tests, due to the additional rope in the knot body tightening around two lengths of rope in the termination knot (see Fig. 1). This effect is much more pronounced in the quasistatic test than in the dynamic behavior, suggesting that the slower test may allow for more reorientation within the knot body than the dynamic scenario. As such, quasistatic tests on knotted ropes should be extended to dynamic scenarios with caution.

These results have important implications for standardized testing of ropes and fall protection equipment where a knot is incorporated and the pass-fail criteria includes maximum load experienced. For example, the ISO 22159 [38] and EN892 [39] that are used in descent device and rope characterization testing (and referenced in other standards such as NFPA 1983 [24] and UIAA 101 [33]) require the rope samples to be terminated with a figure- 8 on a bite. From the above results at a 0.25 fall factor, the figure- 8 on a bite is capable of absorbing enough energy to reduce the MAL by approximately $2.4 \mathrm{kN}$ with the Technora based ropes compared to the baseline configuration with clamped ends. While different standards require different fall factors and drop masses, it is apparent that the energy absorbed by the knotted termination should be considered. When testing life safety rope performance, knots are often considered a difficult to control variable. This study has quantified this variability and presents new and useful information on knotted rope performance, providing an opportunity to use knots as a solution rather than an uncontrolled variable.

Future studies may expand this research to investigate the combined effects of descent control devices and knots as well as different types of knots on a single rope in further reducing dynamic impact loads. Additional studies may expand on the effects of subsequent impact events on the same system and the knots' ability to continue to absorb sufficient energy. The purpose of the current study was not to conduct a detailed statistical analysis of the data. Positive results reported here suggest that additional analyzes be conducted on knots of interest (such as the quadruple overhand) with larger sample sizes. Additionally, Monte Carlo methods may be utilized with the collected MBS and MAL data for these rope/knot combinations to provide a more rigorous method of estimating probability of failure as well as probability of injuring a firefighter.

\section{Conclusion}

We present a study on the effect of knots incorporated in rope systems for impact energy absorption purposes. This study has confirmed previous research that incorporating knots in rope will significantly reduce the breaking strength, but significantly larger reductions in strength were measured in stiff high temperature Technora-based ropes compared to previous studies where more compliant climbing and maritime ropes were investigated. Knots with larger minimum bend radius are shown to have a less significant impact on strength reduction. A compact termination knot that incorporates a large area for energy dissipation within the knot body (quadruple overhand) was shown to have a higher minimum breaking strength and reduced variability compared to the manufacturer sewn-eye terminations.

These same knots were found to significantly reduce the maximum arresting loads from a relatively small (but typical) fall by $4.0-6.3 \mathrm{kN}$ for Technora-Technora and $1.4-1.8 \mathrm{kN}$ for Technora-Nylon compared to the baseline sewn-eye configuration. The quadruple overhand knots were shown to have the largest reduction in arrest load from the impact event. Importantly, the ratio of MAL to MBS was lower for nearly all knot configurations when compared to the manufacturer sewn-eye termination, suggesting that the impact load from the standard drop test is reduced more significantly than the strength of the rope. The most significant arrest load reduction was measured in the Technora-Technora samples where the MAL/MBS ratio was $80 \%$ for the manufacturer sewn-eye, yet reduced to $33 \%$ for the quadruple overhand termination. Rope systems can incorporate such knots to help absorb energy in a compact, cost effective manner and could be considered in other industrial and sport applications.

Acknowledgments This research was funded by the Department of Homeland Security's Assistance to Firefighters Grant Program's Fire Prevention and Safety Grants through Grant \# EMW-2008-FP-02504. The authors also thank Greg Milner and his team at the Aerospace Engineering Machine Shop with the construction of key testing apparatus components. 


\section{References}

1. U.S. Department of Labor, Occupational Safety and Health Administration (OSHA) (1995) 29 CFR Parts 1910 and 1926 safety standards for fall protection in the construction industry; 1926.502 Fall protection systems criteria and practices-section (d) personal fall arrest systems. Occupational Safety and Health Administration, Washington, DC

2. Sulowski AC (2006) How good is the $8 \mathrm{kN}$ maximum arrest force limit in industrial fall arrest systems? In: International symposium on fall protection, Seattle

3. Magdefau H (1989) Die Belastung des Meschlichen Korpers Beim Sturz ins Seil und Deren Folgen. Dissertation. LuwigMaximilians-Universitat, Munich

4. Bitting K (1980) The dynamic behavior of nylon and polyester line. United States Coast Guard Research and Development Center, Groton

5. Parsey M (1982) Fatigue of SPM mooring hawsers. In: Fourteenth annual offshore technology conference, pp 71-94

6. Parsey M, Street A, Banfield SJ (1985) Dynamic behavior of Marine Hawsers. In: Seventeenth annual offshore technology conference, vol 3, pp 429-443

7. Davies P, Baizeau R, Grosjean F, Francois M (1999) Testing of large cables for mooring line applications. In: Proceedings of the 1999 ninth international offshore \& polar engineering conference, pp 369-376

8. Chailleux E, Forest B, Davies P (2005) Identification of model parameters for predicting long term behaviour of marine ropes. In: Oceans-IEEE, vol 2, pp 1279-1285

9. Drabble F, Brookfield DJ (2000) Safety of fall arrest systems: a numerical and experimental study. Proc Inst Mech Eng C 214(10):1221-1233

10. Hennessey CM, Pearson NJ, Plaut RH (2005) Experimental snap loading of synthetic ropes. Shock Vib 12(3):163-175

11. Pavier M (1998) Experimental and theoretical simulations of climbing falls. Sports Eng 1(2):79-91

12. Vogwell J, Minguez JM (2007) The safety of rock climbing protection devices under falling loads. Eng Fail Anal 14(6): $1114-1123$

13. Spierings AB, Henkel O, Schmid M (2007) Water absorption and the effects of moisture on the dynamic properties of synthetic mountaineering ropes. Int J Impact Eng 34(2):205-215

14. Nikonov A, Saprunov I, Zupančič B, Emri I (2011) Influence of moisture on functional properties of climbing ropes. Int J Impact Eng 38(11):900-909

15. Wu HC (1992) An energy approach for rope-strength prediction. J Text Inst 83(4):542-549

16. Abrate S, Dooley R, Kaste R, Thibault G, Millette W (2003) Nonlinear dynamic behavior of parachute static lines. Compos Struct 61(1):3-12

17. Spierings AB, Stämpfli R (2006) Methodology for the development of an energy absorber: application to worker security ropes. Int J Impact Eng 32(9):1370-1383

18. Baszczyński K (2007) Dynamic strength tests for low elongation lanyards. Int J Occup Saf Ergon 13(1):39-48

19. Goh YM, Love PED (2010) Adequacy of personal fall arrest energy absorbers in relation to heavy workers. Saf Sci 48(6): 747-754

20. Baszczyński K, Jachowicz M (2011) Effect of mechanical factors on the protective parameters of textile elements in personal equipment protecting against falls from a height. Fibres Text East Eur 19(5):117-124

21. NIOSH Firefighter Fatality Investigation and Prevention Program (2006) Career lieutenant and career fire fighter die and four career fire fighters are seriously injured during a three alarm apartment firem, New York

22. Horn GP, Chaussidon J, Obstalecki M, Martin DA, Backstrom RG, Kerber S (2015) Evaluating fire service escape ropes at elevated temperatures and fire conditions. Fire Technol. doi:10. 1007/s10694-013-0373-2

23. Martin DA, Obstalecki M, Kurath P, Horn GP (2014) An approach for quantifying dynamic properties and simulated deployment loading of fire service escape rope systems. Exp Tech. doi:10.1111/ext.12073

24. NFPA 1983 (2012) Standard on life safety rope and equipment for emergency services. National Fire Protection Association, Quincy

25. Marbach G, Bernard T (2000) Alpine caving techniques: a complete guide to safe and efficient caving. Speleo Projects, Allschwil

26. Budworth G (1997) The complete book of knots. The Lyons Press, Connecticut

27. Milne KA, McLaren A (2006) An assessment of the strength of knots and splices used as eye terminations in a sailing environment. Sports Eng 9(1):1-13

28. Saitta AM, Soper PD, Wasserman E, Klein ML (1999) Influence of a knot on the strength of a polymer strand. Nature 399(6731):46-48

29. Marturello DM, McFadden MS, Bennett RA, Ragetly GR, Horn G (2014) Knot security and tensile strength of suture materials. Vet Surg 43(1):73-79

30. Brown A (2008) The strength of knots in dynamic climbing rope. http://personal.strath.ac.uk/andrew.mclaren/alasdair_brown_2008. pdf. Accessed 28 Aug 2014

31. Boron K, Obstalecki M, Kurath P, Horn GP (2013) Utilizing knots to reduce dynamic loads in fire service rope systems. In: Conference proceedings of the society for experimental mechanics series, vol 1, pp 433-439

32. Vines T, Hudson S (2004) High angle rescue techniques. Jones \& Bartlett Learning, Massachusetts

33. Union Internationale des Associations d'Alpinisme (UIAA) Safety (2013) UIAA 101, mountaineering and climbing equipment 'Dynamic Ropes', Switzerland

34. Horn GP, Kurath P (2011) Failure of firefighter escape rope under dynamic loading and elevated temperatures. In: Conference proceedings of the society for experimental mechanics series, vol 1 , pp 353-359

35. Weber C, Hudson S (1999) UIAA dynamic drop testing results with loads greater than $80 \mathrm{~kg}$. In: International technical rescue symposium

36. Weber C (2001) Fall factors \& life safety ropes: a closer look. In: International technical rescue symposium

37. Weber C (2002) Analysis of impact force equations. In: International technical rescue symposium

38. International Organization for Standardization (ISO) (2007) Personal equipment for protection against falls—descending devices. ISO 22159:2007

39. British Standards Institution (BSI) (2012) Mountaineering equipment-dynamic mountaineering ropes—safety requirements and test methods. BS EN 892:2012 